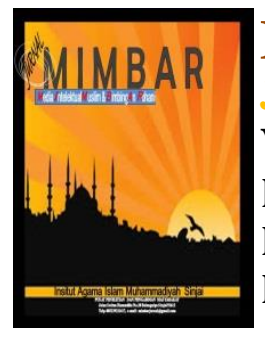

MIMBAR

Jurnal Media Intelektual Muslim dan Bimbingan Rohani

Volume 5, No. 2, 2019

ISSN (print) : 2442-3217

ISSN (online) : 2716-3806

Homepage : http://journal.iaimsinjai.ac.id/indeks.php/mimbar

\title{
MUHAMMADIYAH DALAM PENYEBARAN ISLAM
}

\section{Oleh : Muh.Anis ${ }^{1}$}

Institut Agama Islam Muhammadiyah Sinjai

\begin{abstract}
Abstrak
Muhammadiyah adalah salah satu organisasi Islam yang latar belakang didirikannya dilandaskan pada pengkajian dan pendalaman K.H. Ahmad Dahlan terhadap AlQur'an surat Ali-Imran;104, serta masih ada beberapa faktor lainnya termasuk ketidak bersihan dan campur aduknya kehidupan agama Islam di Indonesia, ketidak efetikfannya lembaga-lembaga pendidikan agama Islam, Aktifitas misi-misi katolik dan protestan, Sikap acuh tak acuh, malah kadang-kadang sikap merendahkan dari golongan intelegensia terhadap Islam. Muhammadiyah dalam melaksanakan dakwahnya banyak menuai keberhasilan terbukti dengan semakin banyaknya amal usaha yang didirikan, namun sampai saat sekarang ini Muhammadiyah mampu bertahan hingga saat sekarang dan senantiasa terus berjuang ditengah tantangan yang semakin kompleks.
\end{abstract}

Kata Kunci : Muhammadiyah, sejarah berdirinya, perkembangan pergerakan

${ }^{1}$ Dosen tetap STAI Muhammadiyah Sinjai 


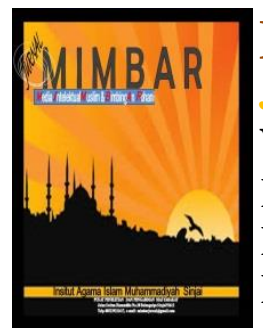

MIMBAR

Jurnal Media Intelektual Muslim dan Bimbingan Rohani

Volume 5, No. 2, 2019

ISSN (print) : 2442-3217

ISSN (online) : 2716-3806

Homepage : http://journal.iaimsinjai.ac.id/indeks.php/mimbar

PENDAHULUAN

\section{A. Latar Belakang Masalah}

Masuknya Islam di Indonesia yang dibawa oleh pedagang dan mubalig Gujarat India, merupakan salah satu faktor yang menentukan ciri khas Islam di Indonesia. Indonesia yang pada waktu itu menganut paham Animisme, Dinamisme, Hindu dan Budha. Dengan mudah menerima Islam sebagai suatu ajaran baru bagi kehidupan mereka. Disamping pemahaman Islam yang dibawa dari Gujarat India, pengaruh paham mistisisme di Indonesia ini pun turut memberi warna bagi kehidupan keagamaan masyarakat. ${ }^{2}$

Kondisi masyarakat pada masa itu yang dalam masa penjajajahan mengakibatkan munculnya berbagai macam pergolakan. Perlawanan politik terhadap kekuasaan yang disemangati oleh aspek keagamaan terus berlangsung. Pada masa ini sejarah umat Islam banyak dikonsentrasikan untuk melawan penjajah. Para ulama mencoba menggerakkan masyarakat melalui waktu-waktu yang sangat menguntungkan dalam pendidikan. Kebangkitan Islam semakin berkembang dengan terbentuknya organisasi keagamaan, secara berurutan organisasiorganisasi tersebut lahir seperti SDI (Sarekat Dagang Islam) di Bogor tahun 1905 dan di Solo 1911, Muhammadiyah di Yogyakarta 1912, Persatuan Islam (Persis) di Bandung 1920, Nahdatul Ulama di Surabaya 1926, dan Persatuan Tarbiyah Indonesia di Bandung, Bukit Tinggi 1930. ${ }^{3}$

Setelah berdirinya SDI yang merupakan organisasi pertama berbasis Islam yang terorganisir secara politik ${ }^{4}$, Muhammadiyah tampil sebagai organisasi sosial, pendidikan dan dakwah yang antara lain diarahkan kepada golongan muslim marginal, termasuk di kalangan priyayi. Maka yang ditempuh oleh organisasi Muhammadiyah adalah menyederhanakan konsep kemusliman. Islam ditampilkan sebagai agama yang mudah dipahami dan mudah dilaksanakan mengingat sasarannya adalah masyarakat kota yang lebih rasional dan lebih sibuk.

\footnotetext{
${ }^{2}$ Mustafa Kamal Pasha dan Ahmad Adaby Darban, Muhammadiyah Sebagai Gerakan Islam (Cet.2, Yogyakarta: Pustaka SM, 2009), h. 68.

${ }^{3}$ Wahyu Ilaihi Dan Harjani Hefni Polah, Pengantar Sejarah Dakwah (Cet. 1, Jakarta: Kencana, 2007, h. 185-186.

${ }^{4}$ Ibid, h. 186.
} 


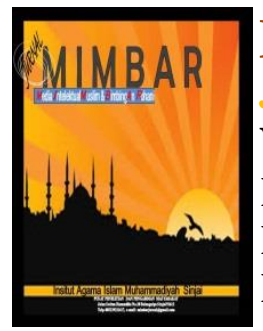

MIMBAR

Jurnal Media Intelektual Muslim dan Bimbingan Rohani

Volume 5, No. 2, 2019

ISSN (print) : 2442-3217

ISSN (online) : 2716-3806

Homepage : http://journal.iaimsinjai.ac.id/indeks.php/mimbar

Muhammadiyahlah yang memasukkan dan memperdalam unsur keagamaan kepada SI dan sebelumnya kepada Budi Utomo. ${ }^{5}$

Muhammadiyah sebagai gerakan Islam modernis memiliki peran yang cukup penting dalam pergerakan perjuangan di Indonesia. Sepak terjang Muhammadiyah dalam kancah perjuangan dan penyebaran Islam ke berbagai daerah di seluruh Indonesia tidaklah mudah, namun membutuhkan perjuangan dan pengorbanan dari tokoh-tokoh yang aktif dalam pergerakan Muhammadiyah terutama dari pendiri organisasi pergerakan ini.

\section{B. Rumusan Masalah}

1. Bagaimana sejarah berdirinya Muhammadiyah?

2. Bagaimana perkembangan pergerakan Muhammadiyah?

3. Apa peran Muhammadiyah dalam penyebaran Islam di Indonesia?

\section{PEMBAHASAN}

\section{A. Berdirinya Muhammadiyah}

Muhammadiyah adalah gerakan modernis Islam yang paling berpengaruh di Indonesia, gerakannya didasari pada sumber pokok ajaran Islam, yaitu Al-Qur'an dan As-Sunnah. Sekalipun tidak anti mazhab, namun Muhammadiyah tidak mengikatkan dirinya pada satu mazhab. Dalam memahami dan melaksanakan ajaran Islam, Muhammadiyah mengembangkan semangat tajdid dan ijtihad, serta menjauhi taqlid. ${ }^{6}$

Dalam menghadapi perbedaan-perbedaan yang sering ditemukan dalam pelaksanaan ajaran Islam, Muhammadiyah mengembangkan sikap toleransi dan tidak memperlihatkan keberpihakan pada satu golongan. Pada prinsipnya setiap ajaran Islam yang di laksanakan haruslah bersumber dari Al-Qur'an dan as-sunnah.

\section{Latar belakang berdirinya Muhammadiyah}

\footnotetext{
${ }^{5}$ M.Dawam Raharjo, Intelektual Intelegensia dan Perilaku Politik Bangsa; Risalah Cendekiawan Muslim (Cet.IV, Bandung; Mizan, 1999), h. 32.

${ }^{6}$ H. M. Amin Rais, Dkk., Dinamika Pemikiran Islam dan Muhammadiyah; Almanak Muhammadiyah Tahun 1997 M./1417-1418 H (Cet.2, Yogyakarta: Lembaga Pusat dan Dokumentasi Pimpinan Pusat Muhammadiyah, 1997), h.v.
} 


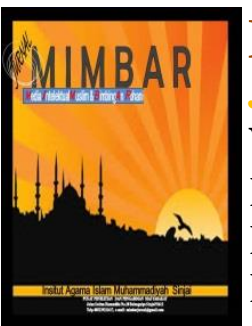

MIMBAR

Jurnal Media Intelektual Muslim dan Bimbingan Rohani

Volume 5, No. 2, 2019

ISSN (print) : 2442-3217

ISSN (online) : 2716-3806

Homepage : http://journal.iaimsinjai.ac.id/indeks.php/mimbar

Pada waktu Muhammadiyah didirikan, keadaan masyarakat Islam sangat menyedihkan, baik dalam bidang politik, ekonomi, sosial, maupun kultural akibat penjajahan Belanda di Indonesia. ${ }^{7}$ Melihat kondisi masyarakat demikian ini menimbulkan keprihatinan bagi beberapa orang tokoh masyarakat hingga terbentuklah beberapa organisasi-organisasi yang bertujuan untuk mengubah kondisi masyarakat terutama untuk membina dan mendidik masyarakat dengan semangat kebangsaan agar bebas dari belenggu penjajah.

Salah satu tokoh pembaharuan itu adalah K.H. Ahmad Dahlan yang mendirikan organisasi Muhammadiyah. Ia lahir di kampung Kauman, Yogyakarta, pada tahun 1968 M dengan nama Muhammad Darwis. Ayahnya adalah K.H. Abu Bakar, seorang Khatib Masjid Besar Kesultanan Yogyakarta, yang apabila dilacak silsilahnya sampai kepada maulana malik Ibrahim. Ibunya bernama Siti Aminah, puteri K.H. Ibrahim Penghulu Kesultanan Yogyakarta. ${ }^{8}$

Beliau adalah sosok yang sangat bijaksana dalam menghadapi problematika umat. Menurut beliau kesalehan tidak diukur dari simbol-simbol agama bahkan ritualitas yang dijalankan oleh seorang penganut agama tetapi dari nilai-nilai mulia yang terefleksi dalam kehidupannya. $^{9}$

Adapun K.H. Ahmad Dahlan memberi nama Muhammadiyah kepada pergerakan Islam yang didirikannya dengan maksud untuk bertafa'ul (berpengharapan baik) dapat mencontoh dan meneladani jejak perjuangannya dalam rangka menegakkan dan menjunjung tinggi agama Islam semata-mata demi terwujudnya Izzul Islam Wal Muslimin, kejayaan Islam sebagai realita dan kemuliaan hidup umat Islam. ${ }^{10}$

Menurut pendapat Ahmad Syafi'i Ma'arif menyatakan bahwa kebangkitan Muhammadiyah merupakan usaha untuk memperbaharui pengertian kaum muslimin tentang

${ }^{7}$ Ibid, h. 16.

${ }^{8}$ Mustafa Kamal Pasha Dan Ahmad Adaby Darban, loc.cit, h. 91.

${ }^{9}$ H.Barsihan Nor, Islam Dan Wacana Modernitas (Cet.1, Makassar; Alauddin University Press, 2011), H. 27.

${ }^{10}$ Mustafa Kamal Pasha Dan Ahmad Adaby Darban, op.cit, h. 99. 


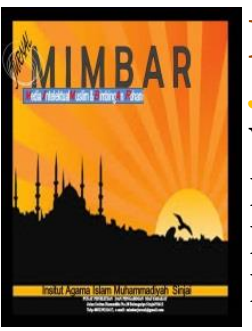

MIMBAR

Jurnal Media Intelektual Muslim dan Bimbingan Rohani

Volume 5, No. 2, 2019

ISSN (print) : 2442-3217

ISSN (online) : 2716-3806

Homepage : http://journal.iaimsinjai.ac.id/indeks.php/mimbar

agamanya, mencerahkan hati dan pikirannya dengan jalan mengenalkan kembali ajaran Islam sejati sesuai dengan dasar Al-Qur'an Dan As-Sunnah. ${ }^{11}$

Muhammadiyah lahir dengan orientasi keagamaan, lebih menampilkan diri sebagai gerakan puritan untuk menghapus beban-beban kultural Islam yang terkena pengaruh budaya agraris. Dari orientasi yang cenderung bersifat keagamaan seperti itu bisa dinilai bahwa Muhammadiyah berupaya untuk melakukan pembaharuan kualitatif yang bersifat keagamaan. Dengan semangat kembali kepada Al-Qur'an dan hadis, Muhammadiyah berupaya keras untuk memurnikan agama dan menghilangkan pengaruh-pengaruh kultural dan simbol-simbol yang tidak relevan dengan Islam agar `dapat lebih dinamis dalam suasana sosial dan kultural yang baru. $^{12}$

Adapun faktor-faktor yang melatar belakangi berdirinya Muhammadiyah terbagi atas dua garis besar ${ }^{13}$ yaitu;

1. Faktor Subyektif, dikatakan juga sebagai faktor utama dan faktor penentu berdirinya Muhammadiyah. Faktor yang dianggap sebagai faktor penentu ini adalah hasil pendalaman K.H. Ahmad Dahlan terhadap Al-Qur'an baik dalam hal gemar membaca maupun menelaah, membahas dan mengkaji kandungan isinya. Ayat-ayat Al-Qur'an ini ditelaah dengan sangat teliti, dipertanyakan asbabun nuzulnya serta apa yang harus dilakukan setelahnya. Salah satu ayat yang diperhatikan oleh K.H.Ahmad Dahlan adalah surat Ali Imran (3), ayat 104;

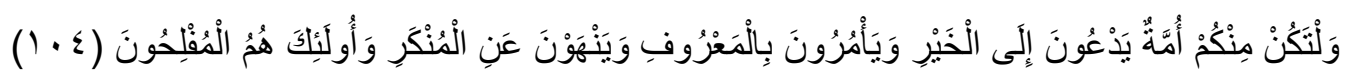

Terjemahnya:

Dan hendaklah ada di antara kamu segolongan umat yang menyeru kepada kebajikan, menyuruh kepada yang ma'ruf dan mencegah dari yang munkar merekalah orang-orang yang beruntung. ${ }^{14}$

\footnotetext{
${ }^{11}$ H.M.Amin Rais, Dkk. loc.cit, h. V.

${ }^{12}$ Kuntowijoyo, Paradigma Islam; Interpretasi Untuk Aksi (Cet.VIII, Bandung; Mizan, 1998), h. 196.

${ }^{13}$ Mustafa Kamal Pasha dan Ahmad Adaby Darban, loc.cit, h. 100-106.

${ }^{14}$ Departemen Agama RI, Al-Qur'an Dan Terjemahnya (Cet.13,Jakarta: Darus Sunnah, 2012), H. 64.
} 
Memahami seruan ayat tersebut K.H. Ahmad Dahlan tergerak hatinya untuk membangun sebuah perkumpulan, organisasi, atau persyarikatan yang teratur dan rapi yang tugasnya berkhidmat melaksanakn misi dakwah, amar ma'ruf nahi mungkar di tengah-tengah masyarakat luas. ${ }^{15}$

2. Faktor Obyektif, beberapa sebab yang bersifat obyektif yang melatar belakangi berdirinya Muhammadiyah yang dikelompokkan dalam dua faktor yakni

a. Faktor internal, yakni faktor yang muncul ditengah-tengah kehidupan umat Islam seperti ketidakmurnian amalan Islam akibat tidak dijadikannya Al-Qur'an dan AsSunnah sebagai satu-satunya rujukan oleh sebagian besar umat Islam Indonesia dan lembaga pendidikan yang dimiliki umat Islam belum mampu menyiapkan generasi yang siap mengemban misi selaku "khalifah Allah diatas bumi".

b. Faktor eksternal, yakni faktor-faktor penyebab yang ada diluar tubuh masyarakat Islam Indonesia, seperti semakin meningkatnya gerakan kristenisasi ditengahtengah masyarakat Indonesia, penetrasi bangsa-bangsa Eropa, terutama bangsabangsa Belanda ke Indonesia, pengaruh dan gerakan pembaharuan dalam dunia Islam.

Menurut pendapat Prof. Mukti Ali seperti dikutip Dr. Haedar Nashir menyatakan bahwa ada empat faktor yang cukup menonjol yang melatar belakangi berdirinya Muhammadiyah, yaitu:

a. Ketidak bersihan dan campur aduknya kehidupan agama Islam di Indonesia.

b. Ketidak efetifannya lembaga-lembaga pendidikan agama Islam.

c. Aktifitas misi-misi katolik dan protestan.

d. Sikap acuh tak acuh, malah kadang-kadang sikap merendahkan dari golongan intelegensia terhadap Islam. ${ }^{16}$

\footnotetext{
${ }^{15}$ Mustafa Kamal Pasha dan Ahmad Adaby Darban, op.cit, $h .100$.

${ }^{16}$ Haedar Nashir, Muhammadiyah Gerakan Pembaruan (Cet.I, Yogyakarta; Suara Muhammadiyah, 2010),
} H. 36. 


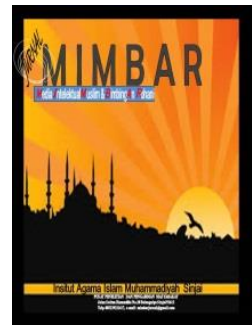

MIMBAR

Jurnal Media Intelektual Muslim dan Bimbingan Rohani

Volume 5, No. 2, 2019

ISSN (print) : 2442-3217

ISSN (online) : 2716-3806

Homepage : http://journal.iaimsinjai.ac.id/indeks.php/mimbar

Adapun latar belakang lahirnya Muhammadiyah di Sulawesi Selatan berawal dari adanya penetrasi bangsa Eropa khususnya Belanda, dalam birokrasi atau kebijakan pemerintah Hindia Belanda terhadap Islam, berwajah ganda, yakni;

a. Sosialisasi kultural dan politik Hindia Belanda ke Nederland.

b. Missionarisasi agama.

Hal ini berdampak pada terjadinya domestikasi kaum ulama ke dalam pemerintah Belanda. Fungsi dari ulama kraton menjadi birokrasi pemerintah. Serta munculnya Islam kota atau Islam modern yang secara lebih langsung melemahkan kekuatan politik ulama. Islam kota ini tumbuh dalam akar kultural yang sangat berlainan dengan sebelumnya. Mereka mulai mengenal ide-ide Barat melalui pendidikan Barat. Pada awal abad 20, struktur sosial- politik menggantikan peran ulama dan para bangsawan tradisional, yang dikenal tiga pemimpin politik dalam masyarakat, yaitu;

a. Kaum intelektual baru yang berfaham sekuler keluaran lembaga-lembaga pendidikan modern termasuk di luar negeri (Belanda).

b. Golongan Islam modern yang lahir dari gerakan reformisme pemikiran Islam dan Islam tradisional yang tetap memegang tradisi sebagai reaksi terhadap pembaharuan Islam, yang juga banyak mengecap pendidikan modern.

c. Kelompok status guo yang disokong oleh Belanda. Hal-hal inilah yang melatar belakangi berdirinya gerakan-gerakan Islam seperti Serikat Dagang Islam (SDI) pada tahun 1909, serikat Islam (SI) tahun 1911, Muhammadiyah tahun 1912 dan Nahdatul Ulama (NU) pada tahun 1962.

Di Bulukumba di dirikan organisasi SADAR yang akhirnya berubah menjadi Muhammmadiyah yang diketuai Muhammmadd Nor di Ponre. Yang melakukan dakwah lewat pendidikan dengan memberantas buta huruf dan membentuk taman bacaan, mendirikan Mushallah dan lebih menggiatkan tabligh atau ceramah keliling kampung sekitar distrik Gantarang pada tahun 1930. Pengurus organisasi SADAR berusaha mengadakan sekolah lebih teratur, maka bermohon kepada pemerintah setempat. Karena Kontroleur Bulukumba menyatakan bahwa pemerintah hanya bisa memberi izin membuka sekolah hanya kepada organisasi yang diakui oleh pemerintah. Maka sepekatlah para pengurus`SADAR mengalihkan 


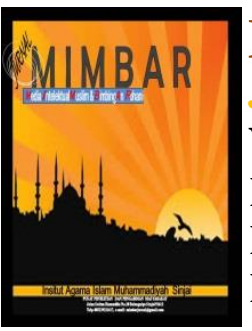

MIMBAR

Jurnal Media Intelektual Muslim dan Bimbingan Rohani

Volume 5, No. 2, 2019

ISSN (print) : 2442-3217

ISSN (online) : 2716-3806

Homepage : http://journal.iaimsinjai.ac.id/indeks.php/mimbar

organisasi itu menjadi Muhammadiyah, maka Muhammad Nor bersama dengan Muhammad

Qasim ke Makassar menemui K.H. Abdullah menyampaikan kesepakatan tersebut dan minta agar Muhammmadiyah Graup Ponre diresmikan. Maka pada bulan februari 1932 Muhammadiyah Group Ponre diresmikan oleh Mansyur Yamani dari Yogyakarta. ${ }^{17}$

Gagasan pembaharuan Muhammadiyah untuk memurnikan agama dari syirik, bid'ah, dan khurafat pada dasrnya merupakan rasionalisasi yang berhubungan dengan ide mengenai perubahan sosial dari masyrakat agraris ke masyarakat industrial atau dari masyrakat tradisional kemasyarakat modern. Dari itu Muhammadiyah dalam pergerakannya banyak mendirikan sekolah-sekolah, karena kesadaran bahwa untuk hidup didalam masyrakat industrial, orang harus belajar melalui pendidikan formal yang mengajarkan keterampilan-keterampilan tertentu. ${ }^{18}$

\section{Pengertian Muhammadiyah}

Muhammadiyah adalah salah satu organisasi Islam yang cukup banyak dikenal baik oleh kaum intelektual maupun oleh kaum awam. Namun terkadang terjadi kesalahpahaman terhadap ajaran-ajaran yang dianggap paham dari Muhammadiyah dikarenakan oleh kekeliruan dalam memahami makna dari Muhammadiyah itu sendiri.

Adapun arti dari Muhammadiyah dapat dilihat dari dua aspek yaitu aspek bahasa dan aspek istilah (terminology). Menurut bahasa Muhammadiyah berasal dari bahasa Arab "Muhammad" yaitu nama Nabi dan Rasul Allah yang terakhir. Kemudian mendapat "ya" nisbiyah yang artinya menjeniskan. Jadi Muhammadiyah berarti umat Muhammad saw atau pengikut Muhammad saw, yakni semua orang Islam yang mengakui dan meyakini bahwa Nabi Muhammad saw adalah hamba dan pesuruh Allah yang terakhir. ${ }^{19}$

Sedangkan menurut Istilah Muhammadiyah diartikan sebagi gerakan Islam, dakwah amar ma'ruf dan nahi mungkar, beraqidah Islam dan bersumber pada Al-Qur'an dan sunnah, didirikan

\footnotetext{
${ }^{17}$ Muliaty Amin, Teori-Teori Ilmu Dakwah (Cet.1, Makassar; Aluddin University Press, 2011), h. 189-191.

${ }^{18}$ Kuntowijoyo, Paradigma Islam ; Interpretasi Untuk Aksi (Cet.VIII, Bandung; Mizan, 1998), h. 268-269.

${ }^{19}$ Mustafa Kamal Pasha Dan Ahmad Adaby Darban, Muhammadiyah Sebagai Gerakan Islam (Cet.2, Yogyakarta: Pustaka Sm, 2009), H. 99.
} 


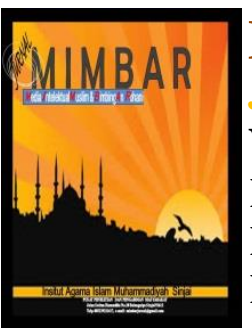

MIMBAR

Jurnal Media Intelektual Muslim dan Bimbingan Rohani

Volume 5, No. 2, 2019

ISSN (print) : 2442-3217

ISSN (online) : 2716-3806

Homepage : http://journal.iaimsinjai.ac.id/indeks.php/mimbar

oleh K.H. Ahmad Dahlan pada tanggal 18 Dzulhijjah 1330 Hijriyah bertepatan dengan tanggal 18 november 1912 Miladiyah di kota Yogyakarta. ${ }^{20}$

Kebangkitan Muhammadiyah Menurut pendapat Ahmad Syafi'i Ma'arif merupakan usaha memperbaharui pengertian kaum muslimin tentang agamanya, mencerahkan hati dan pikirannya dengan jalan mengenalkan kembali ajaran Islam sejati sesuai dengan dasar al-qur'an dan as-sunnah. ${ }^{21}$

Sebagaimana layaknya suatu organisasi, Muhammadiyah memiliki lambang tersendiri yang mencerminkan identitasnya. Lambang Muhammadiyah yaitu matahari yang memancarkan duabelas sinar yang mengarah ke segala penjuru, dengan sinar yang putih bersih bercahaya, ditengah-tengah matahari terdapat tulisan dengan huruf Arab; Muhammadiyah, pada lingkaran atas yang mengelilingi tulisan muhammadiyah terdapat tulisan berhuruf Arab, berujud kalimat tauhid, yang seluruhnya terletak pada warna dasar hijau. ${ }^{22}$

Adapun makna dari lambang Muhammadiyah ini adalah seperti matahari yang memiliki kekuatan memancarkan sinar panas yang sangat berguna bagi kehidupan biologis semua makhluk hidup yang ada di bumi, Muhammadiyah berharap akan menjadi penyebab lahir dan berlangsungnya kehidupan spiritual, rohaniah bagi semua orang yang mau menerima pancaran sinarnya yang berupa ajaran Islam sebagaimana yang termuat dalam Al-Qur'an dan As-Sunnah. Adapun makna dari duabelas sinar matahari yang memancar keseluruh penjuru mengibaratkan tekad dan semangat pantang menyerah dari warga Muhammadiyah dalam memperjuangkan Islam di tengah-tengah masyarakat bangsa Indonesia. Sedangkan sinar putih pada seluruh gambar melambangkan kesucian dan keikhlasan dan warna hijau yang menjadi warna dasar melambangkan kedamaian dan kesejahteraan. ${ }^{23}$

Menganalisa latar belakang berdirinya sampai kepada makna dari simbol-simbol pada lambang Muhammadiyah mengisyaratkan pada kemuliaan tujuan pendirian pergerakan

\footnotetext{
${ }^{20}$ Mustafa Kamal Pasha dan Ahmad Adaby Darban, Muhammadiyah Sebagai Gerakan Islam (Cet.2, Yogyakarta: Pustaka Sm, 2009), h. 99.

${ }^{21}$ H.M.Amin Rais, Dkk. Loc.Cit, h. V.

${ }^{22}$ Mustafa Kamal Pasha dan Ahmad Adaby Darban, Op.Cit, h. 106-107.

${ }^{23}$ Ibid, h. 107-108.
} 


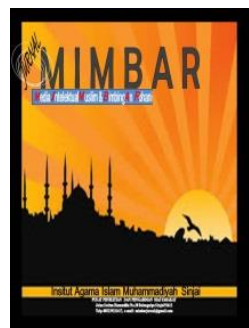

MIMBAR

Jurnal Media Intelektual Muslim dan Bimbingan Rohani

Volume 5, No. 2, 2019

ISSN (print) : 2442-3217

ISSN (online) : 2716-3806

Homepage : http://journal.iaimsinjai.ac.id/indeks.php/mimbar

Muhammadiyah yang berkeinginan mengembalikan umat Islam pada fitrahnya dengan berpedoman pada Al-Qur'an dan As-Sunnah.

\section{B. Perkembangan Pergerakan Muhammadiyah}

Muhammadiyah yang pada langkah awalnya merupakan suatu organisasi yang berupaya melakukan pembaharuan kualitatif akhirnya menimbulkan dampak kuantitatif yakni banyak menimbulkan dampak sosial. Hal ini disebabkan Muhammadiyah dari gerakan pemurnian telah menciptakan lembaga-lembaga dan tradisi-tradisi baru dengan dukungan organisasi modern. ${ }^{24}$

Usaha-usaha yang dilakukan disamping dalam bidang pendidikan yakni lebih banyak menekankan pada pemurnian tauhid dan ibadah dalam Islam. Dalam konsep praktis, agar dakwah Islam diera informasi sekarang tetap relevan, efektif, dan produktif, M.Amin Rais menawarkan lima pekerjaan rumah yang perlu diselesaikan dalam bukunya moralitas politik Muhammadiyah, yaitu:

a. Perlu ada pengkaderan yang serius untuk memproduksi juru-juru dakwah dengan pembagian kerja yang rapi. Ilmu dakwah tidak cukup mendukung proses dakwah, melainkan perlu didukung oleh oleh berbagai penguasaan dalam teknologi informasi yang mutakhir.

b. Setiap organisasi Islam yang berminat dalam tugas-tugas dakwah perlu membangun laboratorium dakwah.

c. Proses dakwah tidak lagi terbatas pada dakwah bi al-lisan, tapi harus diperluas dengan dakwah bi al-hal, bi al-khitabah (lewat tulisan), bi al-hikmah (dalam arti politik) bi aliqtishhadiyah (ekonomi), dan sebagainya.

d. Media massa cetak dan terutama media elektronik harus dipikirkan sekarang sebagai media dakwah.

e. Merebut remaja Indonesia adalah tugas dakwah jangka panjang. ${ }^{25}$

Lima dokrtrin yang senantiasa dipegang teguh oleh warga Muhammadiyah ini mengantarkan Muhammadiyah dalam melaksanakan pergerakannya telah banyak menuai

\footnotetext{
${ }^{24}$ Kuntowijoyo, loc.cit, h.197.

${ }^{25}$ Nurhidayat Muhammad Said, Dakwah \& Efek Globalisasi Informasi (Makassar: Aluddin University
} Press, 2011), h. 117-119. 


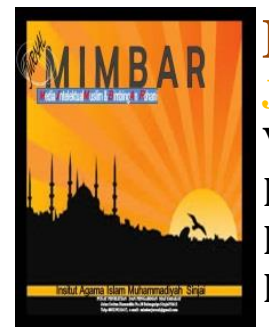

MIMBAR

Jurnal Media Intellektual Muslim dan Bimbingan Rohani

Volume 5, No. 2, 2019

ISSN (print) : 2442-3217

ISSN (online) : 2716-3806

Homepage : http://journal.iaimsinjai.ac.id/indeks.php/mimbar

keberhasilan meski belum mencapai hasil yang ideal mengingat kondisi masyarakat yang dihadapi sekarang berbeda dengan kondisi masyarakat ketika Muhammadiyah didirikan. Untuk itu lima langkah yang digagas oleh Dr.Amin Rais tersebut adalah merupakan suatu solusi dalam menghadapi kondisi umat dewasa ini.

\section{Peran Muhammadiyah dalam Penyebaran Islam di Indonesia}

Melirik pada kondisi masyarakat ketika Muhammadiyah mulai didirikan, dimana kehidupan masyarakat yang jauh dari pelaksanaan syariat Islam yang murni, kejumudan, dan keterbelakangan, maka dapat dikatakan bahwa Muhammadiyah sebagai suatau gerakan pembaruan dalam Islam telah banyak menapak keberhasilan. Hal ini dapat dilihat dari berbagai amal Usaha Muhammadiyah yang telah banyak didirikan.

Sebagai organisasi, jam'iyyah, persyarikatan, dan harakah (gerakan), menurut Dr.H.M. Amin Rais, Muhammadiyah memegang teguh lima doktrin yang senantiasa dipegang teguh oleh kalangan warga Muhammadiyah ${ }^{26}$, yaitu;

a. Tauhid; dalam wawasan keagamaan Muhammadiyah, tauhid adalah masalah paling kunci. Tauhid yang jernih dan benar akan melahirkan kehidupan yang bersih, seimbang, dan adil serta sejahtera sebaliknya bila tauhid terkena polusi syirik kehidupan umat Islam akan mengalami degradasi dan degenerasi di segala bidang.

b. Pencerahan umat; dalam mencerdaskan dan mencerahkan kehidupan umat Islam, Muhammadiyah menempuh tiga proses pendidikan sekaligus yakni taklim, tarbiyah, dan ta'dib. Taklim berusaha mencerdasakan otak manusia, tarbiyah mendidik perilaku yang benar, sedangkan ta'dib memperhalus adab kesopanan.

c. Menggembirakan amal saleh; doktrin iman tanpa amal saleh bagaikan pohon tanpa buah sangat dipegang kuat oleh warga muhammadiyah. Dalam Anggaran Rumah Tangga (ART) Muhammadiyah, syarat berdirinya sebuah ranting Muhammadiyah adalah dimilikinya sebuah amal usaha, walaupun hanya sebuah Madrasah Ibtida'iyah atau taman kanak-kanak.

d. Kerja sama untuk kebajikan; kerjasama Muhammadiyah berdimensi empat yaitu kerjasama internal Muhammadiyah dengan seluruh organisasi otonomnya dan juga antar

${ }^{26}$ M.Amin Rais, dkk, loc.cit, h. 1-6. 


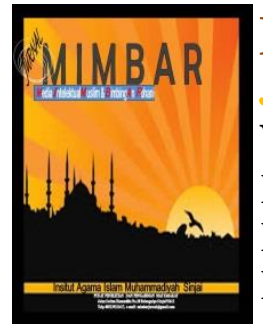

MIMBAR

Jurnal Media Intelektual Muslim dan Bimbingan Rohani

Volume 5, No. 2, 2019

ISSN (print) : 2442-3217

ISSN (online) : 2716-3806

Homepage : http://journal.iaimsinjai.ac.id/indeks.php/mimbar

majelis dan antar lembaga dalam tubuh Muhammadiyah sendiri, kerjasama dengan seluruh organisasi Islam dalam rangka memperkokoh ukhuwah Islamiyah, kerjasama dengan seluruh kekuatan sosial termasuk dengan umat beragama lain untuk mengisi kemerdekaan lewat program-program pembangunan nasional, selalu membangun kerjasama dengan pemerintah yang sah.

e. Tidak berpolitik praktis; salah satu rahasia kelestarian dan kestabilan Muhammadiyah terletak pada kepiawaiannya untuk menghindari politik praktis. Pengalaman menunjukkan bahwa bila kepentingan politik sudah masuk ke dalam tubuh sebuah organisasi non-politik maka, maka organisasi tersebut menjadi rawan konflik dan perpecahan.

Muhammadiyah memiliki semboyan "sedikit bicara banyak bekerja" yang benar-benar dibuktikan dengan amaliyah. Seperti dilihat di berbagai bidang yakni bidang keagamaan, bidang pendidikan, bidang kemasyarakatan, bidang politik kenegaraan ${ }^{27}$, sebagai berikut;

a. Bidang keagamaan; bidang ini adalah pusat seluruh kegiatan Muhammadiyah, dasar dan jiwa setiap amal usaha Muhammadiyah. Contoh usaha muhammadiyah dalam bidang keagamaan yaitu terbentuknya majelis tarjih (1927), memberi tuntunan dan pedoman dalam bidang ubudiyah sesuai dengan contoh yang telah diberikan oleh Rasulullah, member pedoman dalam penentuan ibadah puasa dan hari raya dengan jalan perhitungan "hisab" atau "astronomi" sesuai dengan jalan perkembangan ilmu pengetahuan modern, dan masih banyak lagi peran-peran lainnya.

b. Bidang pendidikan; karena tidak mungkin menghapus sistim sekolah umum dan sistim pesantren, maka muhammadiyah menempuh usaha perpaduan antara keduanya yakni mendirikan sekolah-sekolah umum dengan memasukkan kedalamnya ilmu-ilmu keagamaan dan mendirikan madrasah-madrasah yang juga diberi pendidikan pengajaran ilmu-ilmu pengetahuan umum.

c. Bidang kemasyarakatan; usaha-usaha muhammadiyah dalam bidang kemasyrakatan adalah mendirikan rumah-rumah sakit modern, lengkap dengan segala peralatan, mendirikan balai-balai pengobatan, rumah bersalin, apotik dan sebagainya. Usaha yang

\footnotetext{
${ }^{27}$ Mustafa Kamal Pasha dan Ahmad Adaby Darban, loc.cit., h. 116-120.
} 


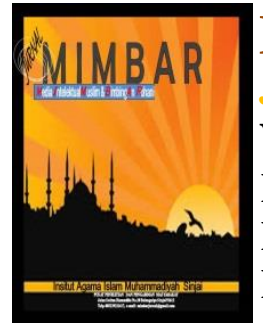

MIMBAR

Jurnal Media Intelektual Muslim dan Bimbingan Rohani

Volume 5, No. 2, 2019

ISSN (print) : :2442-3217

ISSN (online) : 2716-3806

Homepage : http://journal.iaimsinjai.ac.id/indeks.php/mimbar

lain adalah mendirikan panti-panti asuhan anak yatim baik putra maupun putri untuk menyantuni mereka serta masih banyak lagi usaha-usaha dibidang kemasyarakatan yang lainnya.

d. Bidang politik kenegaraan; muhammadiyah bukan organisasi politik, namun dengan segala keyakinannya bahwa agama Islam adalah agama yang mengatur segenap kehidupan manusia di dunia ini maka dengan sendirinya segala hal yang berhubungan dengan dunia juga menjadi bidang garapannya, seperti dalam hal politik kenegaraan meski tetap dalam batas-batasnya sebagai gerakan dakwah islam amar makruf dan nabi mungkar, dan sama sekali tidak bermaksud menjadi sebuah partai politik. Diantara peran Muhammadiyah dalam bidang politik kenegaraan adalah Muhammadiyah menentang dan berhasil membebaskan perkembangan agama Islam dari tekanan pemerintah kolonial Belanda, memperjuangkan peradilan agama Islam untuk penduduk yang beragama Islam, mempelopori berdirinya partai Islam Indonesia, ikut menanamkan rasa nasionalisme dan cinta tanah air Indonesia di kalangan Umat Islam Indonesia dan masih banyak lagi peranperan lainnya yang tidak bisa di sebutkan satu persatu.

Melihat kondisi Muhammadiyah selama dua dekade terakhir, tokoh-tokoh Muhammadiyah misalnya Amin Rais, Watik Pratiknya, Kuntowijoyo, Ahmad Syafii Maarif dan Yahya Muhaimin harus meletakkan dasar-dasar penting guna memungkinkan organisasi berfngsi secara aktif. Pendekatan mereka yang utama adalah;

a. Mengarahkan kembali jalannya semua kegiatan organisasi Muhammadiyah.

b. Mendefenisikan kembali fungsi sosial politiknya, yang sejauh ini secara sederhana dibatasi dalam kerangka amal usaha.

c. Menyegarkan kembali komitmen muhammadiyah kepada semangat tajdid (pembaharuan) yang menjadi cirri khas Muhammadiyah. ${ }^{28}$

Berkat partisipasi langsung generasi yang lebih muda sejak mukhtamar pada akhir 1990, makin Nampak jelas bahwa Muhammadiyah menunjukkan kepeduliannya yang jelas kepada masalah-masalah sosial ekonomi yang lebih luas di Indonesia. Muhammadiyah mendirikan

\footnotetext{
${ }^{28}$ Bahtiar Effendi,Islam dan Negara;Transformasi Pemikiran dan Praktik Politik Islam Di Indonesia (Cet.1, Jakarta: Paramadina, 1998), h. 224.
} 


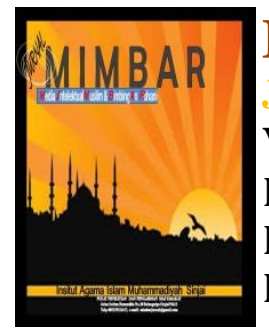

MIMBAR

Jurnal Media Intelektual Muslim dan Bimbingan Rohani

Volume 5, No. 2, 2019

ISSN (print) : 2442-3217

ISSN (online) : 2716-3806

Homepage : http://journal.iaimsinjai.ac.id/indeks.php/mimbar

lembaga-lembaga keuangan yang menyediakan kredit berskala kecil dan menengah seperti BPR.

Selain itu bekerja sama dengan beberapa perusahaan cina (misalnya matahari group, hero supermarket, lippo group), Muhammadiyah juga menyelenggarakan program magang dan pelatihan bagi para anggotanya untuk meningkatkan keterampilan tekhnis dan manajerial dalam kegiatan-kegiatan bisnis dan perdagangan. ${ }^{29}$

Dekade 1980-an selain dengan terbitnya buku-buku Islam serta terbitnya sejumlah majalah, jurnal, tabloid, atau bulletin Islam baru juga ditandai dengan marakanya seminar dan dialog-dialog pemikiran baik intra umat Islam maupun antara umat beragama, yang melibatkan pemikir-pemikir dan ilmuwan baik muslim maupun non-muslim dipusat-pusat pendidikan tinggi dan kota-kota universitas di Indonesia, dialog-dialog yang intens baik formal maupun informal juga terjadi dikalangan nahdatul ulama dan muhammadiyah, kususnya dilingkunayn elite maupun generasi mudanya. Dialog-dialog personal dan intelektual ini sangat besar dampaknya bagi persentuhan pemikiran antara kedua belah pihak. Ditunjang dengan keterbukaan dan pesatnya memperoleh dan mengakses informasi baik dari khazanah tradisional maupun kontemporer, dialog dan diskursus berdampak pada semakin mencairnya dikotomi”'tradisionalismodernis" dalam pemikiran kaum muslim. ${ }^{30}$

Di Indonesia, Muhammadiyah telah tersebar dari Aceh sampai Irian Jaya ${ }^{31}$ dan Menurut Ahmad Syafi'I Ma'arif, Muhammadiyah sebagai suatu gerakan Islam sudah merambah ke wilayah ASEAN yakni malasyia, singapura, thailand, dimana Indonesia menjadi patron dan kiblat Muhammadiyah di ASEAN. Di berbagai wilayah Muhammadiyah baik tingkat propinsi maupun tingkat kabupaten telah dibangun sepuluh ribu lembaga pendidikan dari tingkat TK, TPA, sampai perguruan tinggi. ${ }^{-32}$

Ahmad Dahlan menganggap pembentukan kepribadian sebagi target penting dari tujuantujuan pendidikan. Ia berpendapat bahwa tak seorang pun dapat mencapai kebesaran di dunia ini

\footnotetext{
${ }^{29}$ Bahtiar Effendi,Islam Dan Negara;Transformasi Pemikiran Dan Praktik Politik Islam Di Indonesia (Cet.1, Jakarta: Paramadina, 1998), h. 225.

${ }^{30}$ M. Syafi'i Anwar, Pemikiran dan Aksi Islam Indonesia: Sebuah Kajian Politik Tentang Cendekiawan Muslim Orde Baru (Cet.1, Jakarta; Paramadina, 1995), h. 125.

${ }^{31}$ H.M.Amin Rais, loc.cit, h.23.

${ }^{32}$ Ibid, h. 9.
} 


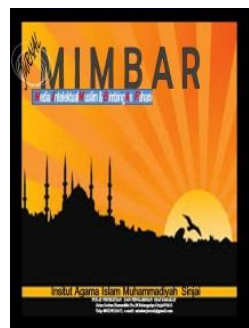

MIMBAR

Jurnal Media Intelektual Muslim dan Bimbingan Rohani

Volume 5, No. 2, 2019

ISSN (print) : 2442-3217

ISSN (online) : 2716-3806

Homepage : http://journal.iaimsinjai.ac.id/indeks.php/mimbar

dan di akhirat kecuali mereka yang memiliki kepribadian yang baik. Seorang yang berkepribadian yang baik adalah yang mengamalkan ajaran-ajaran AL-Qur'an dan Hadits. ${ }^{33}$

Cita-cita dan harapan K.H. Ahmad Dahlan ini yang mengakar pada generasi-generasi Muhammadiyah yang sebagai gerakan tajdid, orientasi dakwahnya meliputi purifikasi dan dinamisasi, ${ }^{34}$ sehingga pada tanggal 24-27 januari 2002, secara formal dakwah kultural digagas dan menjadi keputusan sidang Tanwir di Denpasar Bali yang fokus dakwahnya pada penyadaran iman sehingga umat bersedia menerima dan memenuhi seluruh ajaran Islam meliputi aqidah, ibadah, akhlak, dan muamalah dengan memperhatikan tahapan perubahan sosial berdasarkan pluralitas (keanekaragaman) sosial, ekonomi, budaya, dan politik suatu masyarakat sehingga akhirnya tahapan ideal masyarakat Islami dapat tercapai. ${ }^{35}$

Perjuangan Muhammadiyah dalam mewujudkan Islam sebagai rahmatan lilalamin dengan berorientasi pada purifikasi dan dinamisasi menjadikan Muhammadiyah mampu bertahan hingga saat sekarang ini. Sejak berdirinya hingga saat sekarang ini Muhammadiyah telah berkiprah siang dan malam diseluruh lini kehidupan untuk mewujudkan masyarakat Islam yang sebenar-benarnya. Sejumlah hal telah menunjukkan keberhasilan, kendati masih jauh dari ideal dan harus terus diperbaiki, diperbarui, ditingkatkan, dan disempurnakan.

${ }^{33}$ Dody S.Truna \& Ismatu Ropi, Pranata Islam Di Indonesia; Pergulatan Social, Politik, Hukum, dan Pendidikan (Ciputat; Logos Wacana Ilmu, 2002),h.255.

${ }^{34}$ Pimpinan Pusat Muhammadiyah, Dakwah Kultural Muhammadiyah (Cet.1. Yogyakarta; Suara Muhammadiyah, 2005), h. 12.

${ }^{35}$ Ibid, h.2. 


$\begin{array}{ll}\text { MIMBAR } & \text { MIMBAR } \\ \text { Jurnal Media Intelektual Muslim dan Bimbingan Rohani } \\ \text { Volume 5, No. 2, 2019 } \\ \text { ISSN (print) : 2442-3217 } \\ \text { ISSN (online) : 2716-3806 } \\ \text { Homepage : http://journal.iaimsinjai.ac.id/indeks.php/mimbar }\end{array}$

\section{DAFTAR PUSTAKA}

Anwar, M. Syafi'i Anwar, Pemikiran dan Aksi Islam Indonesia: Sebuah Kajian Politik

Tentang Cendekiawan Muslim Orde Baru, Jakarta; Paramadina, 1995

Amin, Muliaty, Teori-Teori Ilmu Dakwah , Makassar; Aluddin University Press, 2011.

Effendi, Bahtiar, Islam dan Negara;Transformasi Pemikiran dan Praktik Politik Islam Di Indonesia, Jakarta: Paramadina, 1998.

Ilaihi, Wahyu Ilaihi dan Polah, Harjani Hefni, Pengantar Sejarah Dakwah, Jakarta: Kencana, 2007.

Jurdi, Fajlurrahman, dkk, Gerakan Sosial Islam; Genealogi Habitus Muhammadiyah, Makassar; PuKAP-Indonesia, 2010.

Kuntowijoyo, Paradigma Islam ; Interpretasi Untuk Aksi , Bandung; Mizan, 1998.

Muhammad Said, Nurhidayat, Dakwah \& Efek Globalisasi Informasi, Makassar: Aluddin University Press, 2011.

Muhammadiyah, Pimpinan Pusat, Dakwah Kultural Muhammadiyah, Yogyakarta; Suara Muhammadiyah, 2005.

Nashir, Haedar, Muhammadiyah Gerakan Pembaruan, Yogyakarta; Suara Muhammadiyah, 2010.

Nor, Barsihan, Islam Dan Wacana Modernitas, Makassar; Alauddin University Press, 2011.

Pasha, Mustafa Kamal Pasha dan Darban, Ahmad Adaby, Muhammadiyah Sebagai Gerakan Islam, Yogyakarta: Pustaka SM, 2009.

Raharjo, M.Dawam Raharjo, Intelektual Intelegensia dan Perilaku Politik Bangsa; Risalah Cendekiawan Muslim, Bandung; Mizan, 1999.

Rais, M. Amin Rais, Dkk., Dinamika Pemikiran Islam dan Muhammadiyah; Almanak Muhammadiyah Tahun 1997 M./1417-1418 H, Yogyakarta: Lembaga Pusat dan Dokumentasi Pimpinan Pusat Muhammadiyah, 1997.

RI, Departemen Agama, Al-Qur'an Dan Terjemahnya, Jakarta: Darus Sunnah, 2012. 